Article

\title{
Multilevel Bipolar Electroforming-Free Resistive Switching Memory Based on Silicon Oxynitride
}

\author{
Nayan C. Das ${ }^{1} \mathbb{D}$, Se-I Oh ${ }^{2}$, Jarnardhanan R. Rani ${ }^{1}$, Sung-Min Hong ${ }^{1}$ and Jae-Hyung Jang ${ }^{1, *}$ \\ 1 Gwangju Institute of Science and Technology, School of Electrical Engineering and Computer Science, \\ Gwangju 61005, Korea; nayan@gist.ac.kr (N.C.D.); rani@gist.ac.kr (J.R.R.); smhong@gist.ac.kr (S.-M.H.) \\ 2 R\&D Division, Future Technology Research Center, SK Hynix Inc., Incheon 467010, Korea; ohseia@naver.com \\ * Correspondence: jjang@gist.ac.kr; Tel.: +82-62-715-2293
}

Received: 30 March 2020; Accepted: 18 May 2020; Published: 19 May 2020

\begin{abstract}
Resistive random-access memory (RRAM) devices are fabricated by utilizing silicon oxynitride $\left(\mathrm{SiO}_{x} \mathrm{~N}_{y}\right)$ thin film as a resistive switching layer. $\mathrm{A} \mathrm{SiO}_{x} \mathrm{~N}_{y}$ layer is deposited on a $\mathrm{p}+-\mathrm{Si}$ substrate and capped with a top electrode consisting of $\mathrm{Au} / \mathrm{Ni}$. The $\mathrm{SiO}_{\mathrm{x}} \mathrm{N}_{\mathrm{y}}$-based memory device demonstrates bipolar multilevel operation. It can switch interchangeably between all resistance states, including direct SET switching from a high-resistance state (HRS) to an intermediate-resistance state (IRS) or low-resistance state (LRS), direct RESET switching process from LRS to IRS or HRS, and SET/RESET switching from IRS to LRS or HRS by controlling the magnitude of the applied write voltage signal. The device also shows electroforming-free ternary nonvolatile resistive switching characteristics having $R_{H R S} / R_{I R S}>10, R_{I R S} / R_{L R S}>5, R_{H R S} / R_{L R S}>10^{3}$, and retention over $1.8 \times 10^{4} \mathrm{~s}$. The resistive switching mechanism in the devices is found to be combinatory processes of hopping conduction by charge trapping/detrapping in the bulk $\mathrm{SiO}_{\mathrm{x}} \mathrm{N}_{\mathrm{y}}$ layer and filamentary switching mode at the interface between the $\mathrm{SiO}_{\mathrm{x}} \mathrm{N}_{\mathrm{y}}$ and Ni layers.
\end{abstract}

Keywords: bipolar; electroforming free; filamentary mode; multilevel; resistive switching

\section{Introduction}

As complementary metal-oxide-semiconductor (CMOS) technology is reaching its size limit, the traditional flash memory used in the present electronics industry is facing physical and technological difficulty in retaining charges in the reduced dimension [1,2]. The resistive random-access memory (RRAM) device, which has a metal-insulator-metal (MIM) structure, has shown huge potential as an alternative to the current nonvolatile memory due to its advantages of superior switching speed, low-power consumption, excellent reliability, and ultimate scaling potential with crossbar array architectures [3]. There has been extensive research on developing technologies to increase the storage density of RRAM, including physical scaling, a multiple stacked structure [4], and multilevel memory cells $[5,6]$.

Among them, research on multilevel storage in a single memory cell has been actively conducted over the past few years. Multilevel storage behavior is particularly beneficial for high-density storage and oxide-based electronic synaptic devices [7,8]. Multilevel charge storage can be achieved by controlling the write voltage [9-11] or the write current [12].

Many combinations of MIM devices have demonstrated resistive switching properties. Among them, silicon-related dielectric materials have shown exceptional resistive switching properties $[13,14]$ as well as compatibility with $\mathrm{Si}$-based CMOS technology. $\mathrm{SiO}_{\mathrm{x}} \mathrm{N}_{\mathrm{y}}$ appears to be a potential candidate for resistive switching memory devices due to the controllability of the band structure by controlling the composition of $\mathrm{SiO}_{x} \mathrm{~N}_{y}$ [15]. Kapoor et al. reported that the presence of oxygen in the silicon nitride layer increases the electron trap density in the metal/ $\mathrm{Si}_{\mathrm{x}} \mathrm{N}_{\mathrm{y}} / \mathrm{SiO}_{2} / \mathrm{Si}$ device [16], which makes $\mathrm{SiO}_{\mathrm{x}} \mathrm{N}_{\mathrm{y}}$ a 
more desirable candidate for resistive switching memory devices. Chen et al. explored the influence of oxygen on the performance of $\mathrm{SiO}_{\mathrm{x}} \mathrm{N}_{\mathrm{y}}$-based RRAMs and reported bistable resistive switching with a resistance switching ratio of about three after 100 cycles [17]. The effect of copper diffusion on the performance of $\mathrm{SiO}_{\mathrm{x}} \mathrm{N}_{\mathrm{y}}$-based RRAMs was investigated by Yang et al., who observed that the devices exhibit bistable resistive switching with an on/off current ratio of about $10^{1.5}$ with the aid of diffused copper after a two-step electroforming process. Without the copper layer, devices do not show any switching properties [18].

The most common bipolar resistive switching mechanism is the formation and rupturing of conductive filaments derived by voltage-driven ion migration [19]. Usually, an electroforming process is required to create the initial conductive filaments in a fresh device before repeatable resistive switching [20]. The electroforming voltage is much higher than the switching voltage after the electroforming process. The high electroforming voltage may induce severe mechanical and electrical stresses in the device, which changes the morphology of the films and possibly damages electrodes of the device [21]. It has also been observed that unexpected resistance states are generated due to the electroforming process, which degrades the device performance [22,23].

Evidently, electroforming-free operation is one of most desirable properties of the RRAM device for practical applications. There are two distinct characteristics of electroforming-free resistive switching. First, the resistances of the pristine state and high-resistance state (HRS) after the RESET process are similar. Second, the initial SET voltage and the succeeding SET voltage should be comparable. These characteristics are mostly credited to internal defects and conduction filament confinement [24]. The electroforming-free behavior has also been found by other researchers in nonstoichiometric metal oxides due to the presence of defects and oxygen ion migration $[25,26]$. To meet the abovementioned characteristics that require comprehensive defect profile control, ion doping [24], thermal treatment [27], optimization of the film thickness [28] and modulation of the fabrication process $[24,29]$ have been investigated.

In this work, we studied electroforming-free operation as well as multilevel operation of a $\mathrm{SiO}_{\mathrm{x}} \mathrm{N}_{\mathrm{y}}$-based RRAM device. Defect-rich $\mathrm{SiO}_{\mathrm{x}} \mathrm{N}_{\mathrm{y}}$ is employed as the resistive switching layer that is sandwiched between a $\mathrm{p}^{+}$silicon substrate and an $\mathrm{Au} / \mathrm{Ni}$ metal layer. With the combination of the $\mathrm{Ni}$ layer and the defect-rich $\mathrm{SiO}_{\mathrm{x}} \mathrm{N}_{\mathrm{y}}$ layer, we successfully incorporate an intermediate resistance state (IRS) between the HRS and low-resistance state (LRS) and eliminate the electroforming process, which requires a high activation voltage [18]. The device exhibits bipolar electroforming-free SET/RESET operational characteristics as well as multilevel digital memory characteristics with an HRS/LRS resistance ratio over $10^{3}$, which is better than that of the $\mathrm{SiO}_{\mathrm{x}} \mathrm{N}_{\mathrm{y}}$-based devices introduced in previous reports $[17,18]$.

In addition, the effect of current and silicon oxynitride thickness on the overall device performance is investigated. Finally, a feasible resistive switching model is proposed to describe the conduction mechanism of the device.

\section{Materials and Methods}

$\mathrm{SiO}_{\mathrm{x}} \mathrm{N}_{\mathrm{y}}$ thin films with thicknesses of 7, 10, and $15 \mathrm{~nm}$ were deposited by plasma-enhanced chemical vapor deposition (PECVD)(Oxford plasmalab system 100 PECVD, Oxford Instruments Plasma Technology, UK, Plasma Technology, $66.7 \mathrm{mi} \cdot$ Yatton, Bristol, UK, BS49 4AP) on a $\mathrm{p}^{+}-\mathrm{Si}$ substrate (boron-doped, $3.0 \mathrm{~m} \Omega \cdot \mathrm{cm}$ ) at $300{ }^{\circ} \mathrm{C}$. The gas mixture, $\mathrm{N}_{2} \mathrm{O} / \mathrm{SiH}_{4} / \mathrm{NH}_{3} / \mathrm{N}_{2}(60 / 400 / 20 / 600 \mathrm{SCCM}$ ), was supplied under a working pressure of $650 \mathrm{mTorr}$ and an RF power of $15 \mathrm{~W}\left(30.6 \mathrm{~W} / \mathrm{mm}^{2}\right)$. The heavily doped $\mathrm{p}^{+}-\mathrm{Si}$ substrate served as the bottom electrode, and a circular-shaped $\mathrm{Au} / \mathrm{Ni}$ $(150 / 40 \mathrm{~nm})$ top electrode with a radius of $50 \mu \mathrm{m}$ was then deposited by e-beam evaporation through a shadow mask. To observe the area dependency, four different sizes of the 10-nm-thick $\mathrm{SiO}_{\mathrm{x}} \mathrm{N}_{\mathrm{y}}$-based devices were also fabricated with a radius of 35, 50, 150, and 225 um, respectively. Separately, 10-nm-thick $\mathrm{SiO}_{\mathrm{x}} \mathrm{N}_{\mathrm{y}}$ films with the same composition were grown on a glass substrate for Fourier transform infrared (FTIR) absorbance spectroscopy measurement. The electrical characteristics 
of the memory devices were measured using a semiconductor parameter analyzer (HP-4155A). (Hewlett-Packard Company, 3000 Hanover Street Palo Alto, CA 94304-1185 USA) Voltage was applied directly to the top electrode while the bottom electrode was grounded.

\section{Results and Discussion}

\subsection{FTIR Measurement of the $\mathrm{SiO}_{x} \mathrm{~N}_{y}$ Film}

The composition of the PECVD-deposited silicon oxynitride films depends on four major factors, (1) the $\mathrm{N}_{2} \mathrm{O}$ gas flow rate, (2) the presence of $\mathrm{N}_{2}$ gas, (3) the ratio of $\mathrm{NH}_{3}$ in the gas mixture, and (4) the deposition temperature. As the literature suggests, the $\mathrm{H}-\mathrm{Si}$ bond is weaker than the $\mathrm{Si}-\mathrm{O}$ bond. The bond dissociation energies for $\mathrm{H}-\mathrm{Si}$ and $\mathrm{Si}-\mathrm{O}$ are 298.49 and $798 \mathrm{~kJ} / \mathrm{mol}$, respectively. Consequently, when the flow rate of $\mathrm{N}_{2} \mathrm{O}$ and $\mathrm{N}_{2}$ in the gas mixture is increased, oxygen replaces the hydrogen bound with silicon, and subsequently dominates in the film [30,31]. The resulting characteristics of the silicon oxynitride films appear to be more similar to oxide layers than nitride films [32].

It has also been reported that with a low flow rate of $\mathrm{NH}_{3}$ and high deposition temperature $\left(>200^{\circ} \mathrm{C}\right)$, less hydrogen is incorporated into the deposited layer, and the electrical properties of the films are improved [33,34].

The results of the Fourier transform infrared (FTIR) absorbance spectroscopy of the $\mathrm{SiO}_{\mathrm{x}} \mathrm{N}_{\mathrm{y}}$ film are shown in Figure 1. The most significant peaks at 850 and $820 \mathrm{~cm}^{-1}$ are assigned to the $\mathrm{Si}-\mathrm{N}$ bond in silicon nitride, but is probably a combination of $\mathrm{Si}-\mathrm{N}$ and $\mathrm{Si}-\mathrm{O}-\mathrm{Si}$ bonding in oxynitride [30,31]. The broadening of the Si-H absorption peak $\left(2200-2300 \mathrm{~cm}^{-1}\right)$ is a result of the distortion of the S-H bonds, caused by the accommodation of both oxygen and hydrogen in the silicon oxynitride film [30]. The characteristic peak of N-H bonds $\left(3300-3400 \mathrm{~cm}^{-1}\right)$ is absent, which indicates that hydrogen is only present in a small amount [32]. The FTIR spectra analysis confirmed that the characteristics of the $\mathrm{SiO}_{\mathrm{x}} \mathrm{N}_{\mathrm{y}}$ film were dominated by oxygen and nitrogen, with little hydrogen [34].

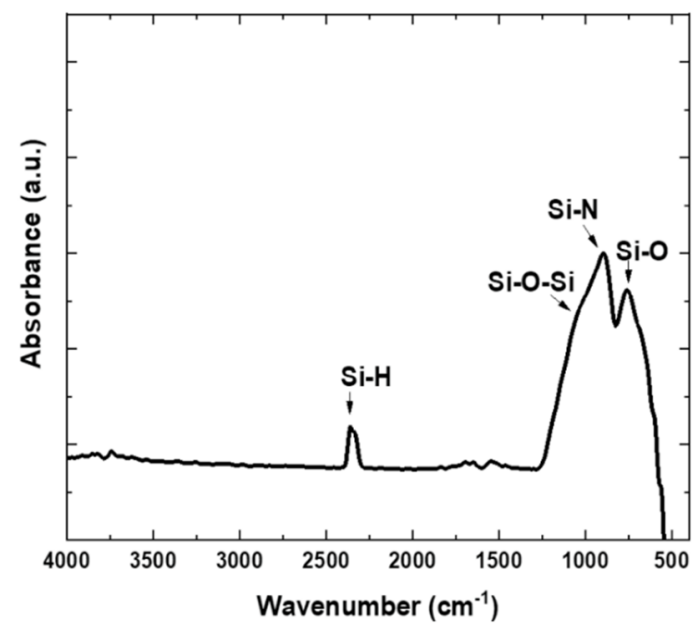

Figure 1. Fourier transform infrared (FTIR) absorbance spectra of silicon oxynitride film.

\subsection{Electrical Characteristics}

The I-V characteristics of the fabricated $\mathrm{Au} / \mathrm{Ni} / \mathrm{SiO}_{\mathrm{x}} \mathrm{N}_{\mathrm{y}} / \mathrm{p}^{+}-\mathrm{Si}$ device were obtained by cycling the applied DC bias voltage according to the sequence of $0 \mathrm{~V} \rightarrow+7 \mathrm{~V} \rightarrow 0 \mathrm{~V} \rightarrow-7 \mathrm{~V} \rightarrow 0 \mathrm{~V}$ with a voltage step of $50 \mathrm{mV}$. The compliance current ( $\mathrm{I}_{\mathrm{COMP}}$ ) was set to $0.25 \mathrm{~mA}$ for positive voltage bias. The multilevel switching operation of the 10-nm-thick $\mathrm{SiO}_{x} \mathrm{~N}_{\mathrm{y}}$ based device (blue) is shown in Figure 2. 


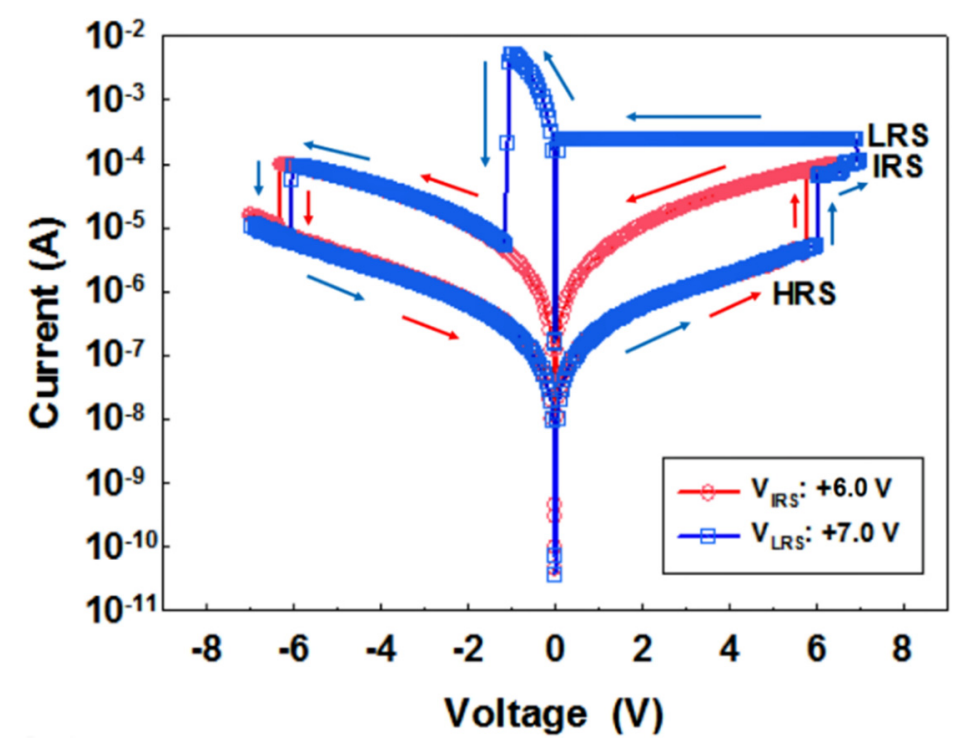

Figure 2. Typical I-V characteristics of an $\mathrm{Au} / \mathrm{Ni} / \mathrm{SiO}_{\mathrm{x}} \mathrm{N}_{\mathrm{y}} / \mathrm{p}^{+}-\mathrm{Si}$ memory device with $\mathrm{I}_{\mathrm{COMP}}=0.25 \mathrm{~mA}$.

The stability of the IRS was confirmed by cycling $0 \mathrm{~V} \rightarrow+6.5 \mathrm{~V} \rightarrow 0 \mathrm{~V} \rightarrow-7 \mathrm{~V} \rightarrow 0 \mathrm{~V}$, which is shown in red. The I-V characteristics exhibit a pronounced electric hysteresis, which is a signature of resistive switching. In particular, it was observed that bipolar multilevel resistive switching can be obtained by controlling the magnitude of the applied voltage.

In the positive bias voltage region, the device was switched from the initial HRS to IRS at around $+6 \mathrm{~V}$, which is called $\mathrm{V}_{\text {IRS. }}$. As the higher positive bias voltage was applied to the device in the IRS, it leads to a sudden increase of current to the compliance current limit at around $+7 \mathrm{~V}$ which is the LRS. In the negative bias voltage region, the current decreases abruptly when the applied voltage reaches around $-1 \mathrm{~V}$, leading to the first RESET process from the LRS to the IRS. As the negative bias voltage reaches $-6 \mathrm{~V}$, the second RESET process occurs from the IRS to the HRS.

The first SET and last RESET voltages of the full cycle of the I-V curve was almost the same as those of the intermediate cycle of the I-V curve. Additionally, the resistance of the initial state and HRS after the second RESET process are also the same $\left(\sim 10^{7} \Omega\right)$, which demonstrates the electroforming-free operational characteristics [24]. Detailed analysis and reasoning on the resistive switching, asymmetric behavior and electroforming-free behavior are discussed in the next subsection.

\subsection{Resistive Switching Mechanism}

$\mathrm{A} \log (\mathrm{I})-\log (\mathrm{V})$ plot of the 10 -nm-thick $\mathrm{SiO}_{\mathrm{x}} \mathrm{N}_{\mathrm{y}}$-based device and current conduction process in the HRS, IRS, and LRS are shown in Figure 3.

The $\log (\mathrm{I})-\log (\mathrm{V})$ characteristics of the device in the HRS and IRS can be clearly divided into different regions which are marked as R-1, R-2, and R-3. It follows the trap-controlled space charge-limited conduction (SCLC) mechanism $[35,36]$. On the other hand, in the LRS, which is marked as $\mathrm{R}-4$, the $\log (\mathrm{I})-\log (\mathrm{V})$ characteristics show an ohmic behavior with a slope of one, which follows the filamentary conduction. The characterization reveals that the resistive switching from the IRS to LRS is caused by controllable transformation from charge trapping/detrapping to filamentary conduction in the $\mathrm{SiO}_{\mathrm{x}} \mathrm{N}_{\mathrm{y}}$-based RRAM device.

The area-dependent current characteristics of $\mathrm{Au} / \mathrm{Ni} / \mathrm{SiO}_{x} \mathrm{~N}_{y} / \mathrm{p}^{+}-\mathrm{Si}$ memory devices is shown in Figure 4. The current of LRS does not depend on the area, which implies that the current conduction in LRS is dominated by the filamentary conduction. It also shows that the resistance switching mechanism between LRS and IRS is the formation and rupture of filaments. On the other hand, area-dependent $\mathrm{I}_{\mathrm{HRS}}$ and $\mathrm{I}_{\text {IRS }}$ support that the current conduction in HRS and IRS is dominated by a trap-to-trap hopping process. [37,38]. 


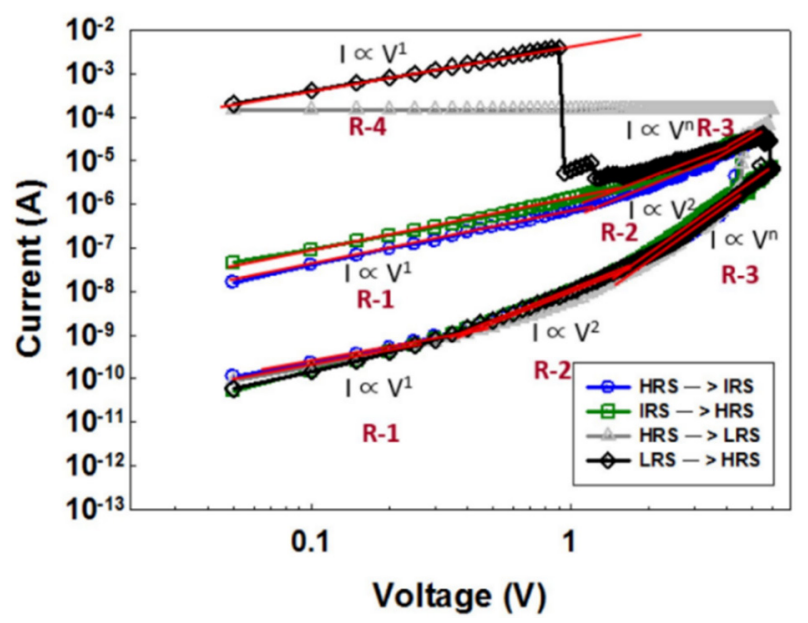

Figure 3. $\log (\mathrm{I})-\log (\mathrm{V})$ characteristics of an $\mathrm{Au} / \mathrm{Ni} / \mathrm{SiO}_{\mathrm{x}} \mathrm{N}_{\mathrm{y}} / \mathrm{p}^{+}-\mathrm{Si}$ memory device with $\mathrm{I}_{\mathrm{COMP}}=$ $0.25 \mathrm{~mA}$.

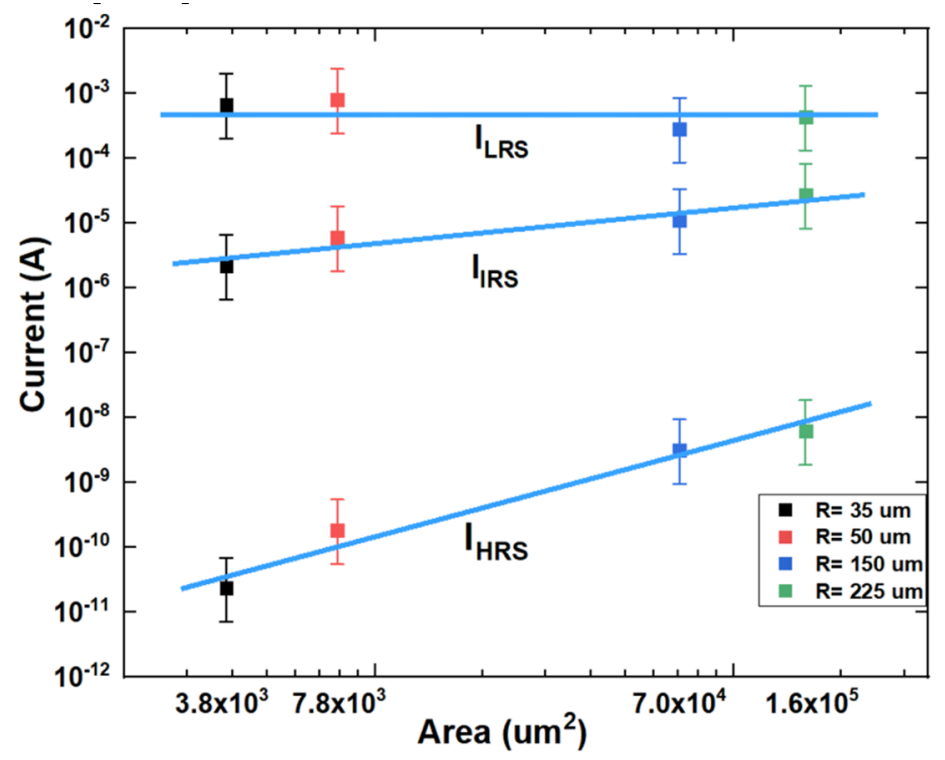

Figure 4. The area dependent current characteristics of $\mathrm{Au} / \mathrm{Ni} / \mathrm{SiO}_{\mathrm{x}} \mathrm{N}_{\mathrm{y}} / \mathrm{p}^{+}-\mathrm{Si}$ memory devices.

Based on analysis of the current conduction mechanism by $\log (\mathrm{I})-\log (\mathrm{V})$ plot and fitting, the total resistive switching mechanism of the device is proposed below, and the schematics are shown in Figure 5. For a detailed understanding of the switching mechanism, the switching from the HRS to IRS was named SET1 and IRS to LRS was named SET2. Similarly, the switching from the LRS to IRS was named RESET1 and IRS to HRS was named RESET2. The as-prepared $\mathrm{Au} / \mathrm{Ni} / \mathrm{SiO}_{\mathrm{x}} \mathrm{N}_{\mathrm{y}} / \mathrm{p}^{+}-\mathrm{Si}$ memory device contained a certain number of defects in its active $\mathrm{SiO}_{\mathrm{x}} \mathrm{N}_{\mathrm{y}}$ layer (Figure $5 \mathrm{a}$ ). As positive bias voltage is applied, the SCLC is controlled by defects. The representative $\log (\mathrm{I})-\log (\mathrm{V})$ characteristics of the SCLC usually involves two different regions. Ohmic conduction $(I \propto V)$ is found in the low-voltage region (R-1). As soon as the voltage goes beyond the trap-filled limit (R-2 region), the $\log (\mathrm{I})-\log (\mathrm{V})$ plot follows Child's square law $\left(I \propto V^{2}\right)$. For further increase in voltage (R-3 region), the Pool-Frenkel emission helps the trapped electrons go to the conduction band by field-enhanced thermal excitation.

As the positive voltage reaches the SET1 voltage $\left(\mathrm{V}_{\mathrm{SET1}}\right)$, the switching from the HRS to IRS takes place. The conduction path originates from the charge-trapping process of the electronic carriers through nitride-related traps in the bulk of the $\mathrm{SiO}_{\mathrm{x}} \mathrm{N}_{\mathrm{y}}$ layer from the bottom electrode to the top electrode (Figure 5b) [35]. The traps are deep enough to store the trapped carriers for a sufficiently long time under repeated read operations. The potential barriers of the traps in the bandgap of the 
switching oxide must be asymmetric with respect to the bias polarity or different levels of discrete trap states. As a result, the trapped carriers respond differently to the applied bias.

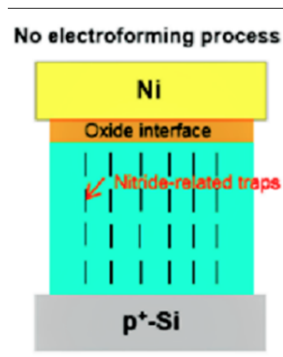

(a) Initial state (HRS)
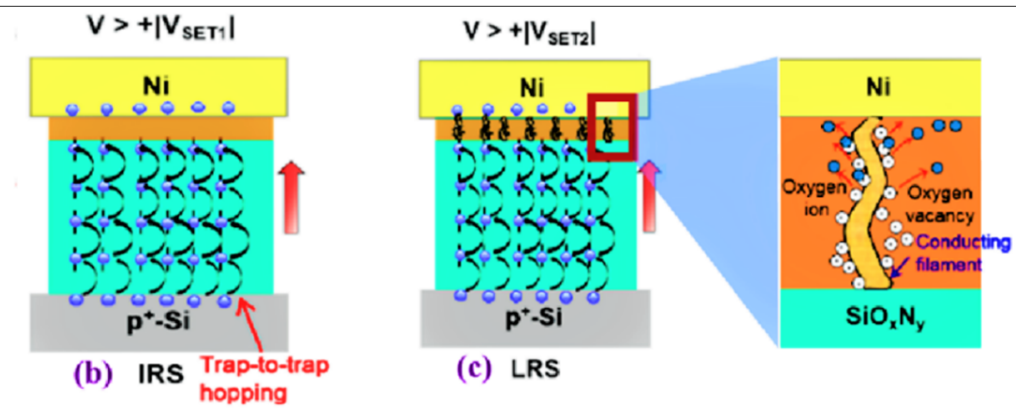

(c) LRS

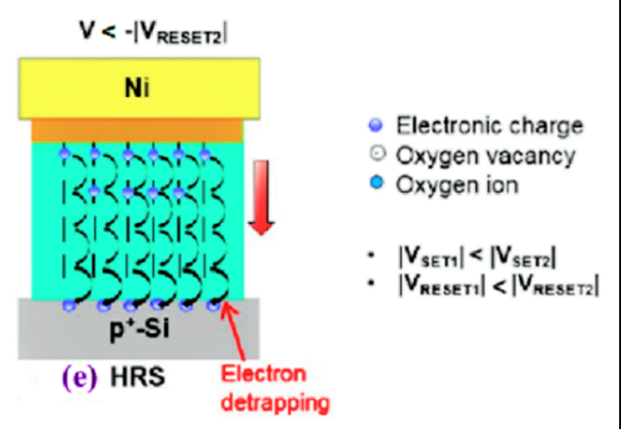

Figure 5. Schematics of the proposed switching mechanism of an $\mathrm{Au} / \mathrm{Ni} / \mathrm{SiO}_{\mathrm{x}} \mathrm{N}_{\mathrm{y}} / \mathrm{p}^{+}-\mathrm{Si}$ memory device.

The electroforming-free resistive switching can be ascribed to the abundant initial nitride-related defects in the PECVD-deposited $\mathrm{SiO}_{\mathrm{x}} \mathrm{N}_{\mathrm{y}}$ layer $[17,30]$. The defects, which are a combination of silicon dangling bonds, are considered as traps in the bulk of the initial $\mathrm{SiO}_{\mathrm{x}} \mathrm{N}_{\mathrm{y}}$ layer [39]. The combination of oxygen and hydrogen with silicon dangling bonds results in a reduction of dangling bonds and traps $[34,36]$. Silicon dangling bonds and oxygen vacancies appear to play major roles for electroforming-free resistive switching.

A gas mixture of $\mathrm{N}_{2} \mathrm{O}: \mathrm{SiH}_{4}: \mathrm{NH}_{3}: \mathrm{N}_{2}$ at a ratio of 3:20:1:30 and a nitrous oxide $\left(\mathrm{N}_{2} \mathrm{O}\right)$ flow rate of 60 SCCM were applied during the PECVD deposition process, which resulted in an oxygen and nitrogen defect-rich $\mathrm{SiO}_{x} \mathrm{~N}_{\mathrm{y}}$ layer with a low amount of hydrogen. This improved the electrical performance of the $\mathrm{SiO}_{x} \mathrm{~N}_{\mathrm{y}}$ layer to the degree that it did not need any additional treatment to achieve electroforming-free resistive switching behavior in the device [34,36].

The switching mechanism is inherently related to the oxygen and nitrogen content in the film. When a positive voltage is increased beyond the $V_{\text {SET1 }}$ value and reaches the $V_{\text {SET2 }}$, resistive switching from IRS to LRS takes place, and conductive filaments of oxygen vacancies $\left(\mathrm{V}_{0}{ }^{+2}\right)$ are formed in the interfacial region between the $\mathrm{Ni}$ and $\mathrm{SiO}_{\mathrm{x}} \mathrm{N}_{\mathrm{y}}$ layers. The $\mathrm{Ni}$ layer acts as a charge reservoir, because of its two stable $\left(\mathrm{Ni}^{2+} / \mathrm{Ni}^{4+}\right)$ oxidation states [40,41].

Oxygen ions travel from the bulk $\mathrm{SiO}_{\mathrm{x}} \mathrm{N}_{\mathrm{y}}$ layer to the Ni layer under the influence of the applied positive voltage to form nonstoichiometric $\mathrm{NiO}_{x}$. Depending on their availability, oxygen ions can bond with $\mathrm{Ni}$ to form $\mathrm{NiO}$, a $\mathrm{Ni}\left(\mathrm{O}_{2}\right)$ complex, and/or nickel dioxide (ONiO) [42]. During the formation of $\mathrm{NiO}$ and $\mathrm{NiO}_{2}$ the changes in the standard molar Gibbs free energy are -211.7 and $-199.0 \mathrm{~kJ} \mathrm{~mol}^{-1}$, respectively, at $289 \mathrm{~K}$ and 1 atmospheric pressure [43]. In electrochemical voltage units, the equivalents of these formation energies are 2.19 and $2.06 \mathrm{~V}$, respectively [44]. The negative Gibbs free energies indicate that the formation of $\mathrm{NiO}_{x}$ is spontaneous.

The high oxygen vacancy density in $\mathrm{SiO}_{x} \mathrm{~N}_{\mathrm{y}}$ can be attributed to Ni oxidation, which accumulates oxygen. Oxygen migration to the Ni layer causes a redox reaction within the conducting filaments, which stimulates the formation of more conductive oxygen vacancy filaments. It is possible that the formation of these conducting filaments occurs within or near the interface layer $[45,46]$. In any case, 
the resistance of the device switches from the IRS to LRS when conducting filaments form in the oxygen-terminated interfacial region (Figure $5 \mathrm{c}$ ).

To break the $\mathrm{NiO}_{x}$ bonds, the same amount of formation energy must be applied in the negative bias direction. The dissociation electrochemical voltages for $\mathrm{NiO}$ and $\mathrm{NiO}_{2}$ are -2.19 and $-2.06 \mathrm{~V}$, respectively [43]. When a negative bias voltage is applied and approaches those values, the oxygen ions travel back from the Ni layer to the interface and recombine with the oxygen vacancies. This capture process ruptures the conducting oxygen vacancy filaments [47-49], leading to resistive switching from the LRS to IRS (Figure $5 \mathrm{~d}$ ). Therefore, no additional electroforming process is required to break the ultrathin $\mathrm{NiO}_{\mathrm{x}}$ layer which is formed in the interfacial region between the $\mathrm{Ni}$ and $\mathrm{SiO}_{\mathrm{x}} \mathrm{N}_{\mathrm{y}}$ layers. Regular bias voltage is enough to form and break the conduction filament through the ultrathin $\mathrm{NiO}_{\mathrm{x}}$ layer. A similar phenomenon was reported by Tran et al., where the oxygen vacancy-based filament formation and annihilation were caused by the migration of oxygen ions/vacancies at the interfacial layer between the $\mathrm{Ni}$ electrode and the active oxide layer depending on the bias voltage [50].

The I-V characteristics in Figure 2 are asymmetric because the voltages required to form and rupture the conducting filaments are different. The SET2 process needed to form a complete conducting filament requires more energy than the RESET1 process. In RESET1, the conducting filament of oxygen vacancies is partially ruptured at the weakest point of the filament, changing the resistance state from LRS to IRS [11,12].

A further increase in the negative bias voltage leads to the RESET2 voltage $\left(\mathrm{V}_{\text {reset2 }}\right)$, where detrapping of the electronic carriers becomes prominent. Here, the conduction path is broken by a charge-detrapping process, and by electronic carriers hopping back through the nitride-related traps of the $\mathrm{SiO}_{\mathrm{x}} \mathrm{N}_{\mathrm{y}}$ layer from the top to the bottom. In turn, the resistance state of the device switches from the IRS to HRS (Figure 5e) [35].

The magnitudes of the voltages required for the SET1 and RESET2 processes are essentially the same because in both cases charges have to cross almost the same distance by hopping [35].

\subsection{Effect of Write-Current Level and Silicon Oxynitride Thickness}

The amount of current that passes through the device needs to be controlled to avoid permanent breakdown during the switching process of the device. It has also been reported that the size and number of conductive filaments can be controlled by the write current in filamentary switching mode [51,52].

The influence of the write current on the resistive switching characteristics of the $\mathrm{Au} / \mathrm{Ni} / \mathrm{SiO}_{\mathrm{x}} \mathrm{N}_{\mathrm{y}}$ $(10 \mathrm{~nm}) / \mathrm{p}^{+}$-Si device is shown in Figure 6, with four write current limits of 0.1, 0.15, 0.25, and $100 \mathrm{~mA}$.

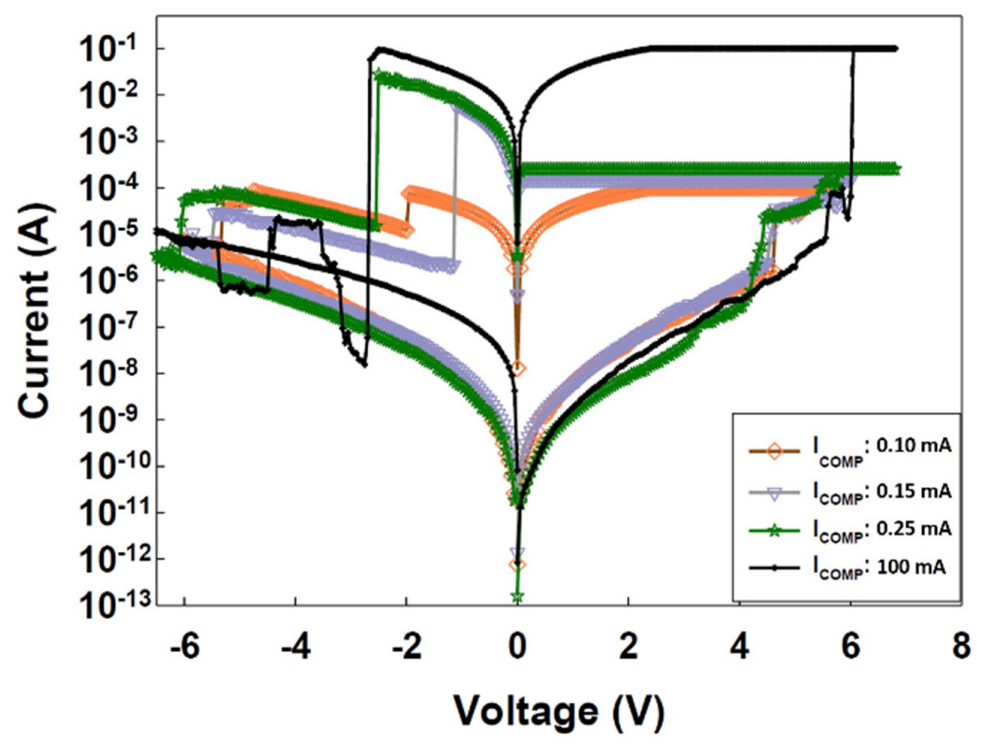

Figure 6. $\mathrm{I}-\mathrm{V}$ characteristics of $\mathrm{Au} / \mathrm{Ni} / \mathrm{SiO}_{\mathrm{x}} \mathrm{N}_{\mathrm{y}} / \mathrm{p}^{+}-\mathrm{Si}$ memory device with various $\mathrm{I}_{\mathrm{COMP}}$ levels. 
The device shows stable multilevel resistive switching states, and the two SET voltages and the second RESET voltage are almost the same regardless of the write currents of $0.1,0.15,0.25 \mathrm{~mA}$. This can be attributed to the presence of enough defects in the $\mathrm{SiO}_{\mathrm{x}} \mathrm{N}_{\mathrm{y}}$.

As the write current increases, the LRS current of the device also increases at the same second SET voltage. This implies that multiple states can be programed by using different levels of write currents. Even at the same SET voltage, the resistance states can be altered by changing the write current level.

However, the device loses multilevel operational characteristics and shows only bistable resistive switching behavior when the device is subjected to the write current of $100 \mathrm{~mA}$. The IRS state does not exist anymore. This indicates that the resistive switching mechanism may change completely from charge trapping and trap-to-trap hopping to filamentary switching inside the bulk $\mathrm{SiO}_{\mathrm{x}} \mathrm{N}_{\mathrm{y}}$ after the device conducts current as high as $100 \mathrm{~mA}$. The most apparent reason could be that the intrinsic defect sites involving charge hopping conduction in the IRS are damaged by the formation of large conductive filaments. The effects of write current on the resistance switching mechanisms were also observed by other researchers [53,54]. Based on these results, it is inferred that the resistive switching from the HRS to LRS is correlated with the filamentary model.

The I-V characteristics of $\mathrm{SiO}_{x} \mathrm{~N}_{y}$-based memory devices having various $\mathrm{SiO}_{\mathrm{x}} \mathrm{N}_{\mathrm{y}}$ thicknesses are compared in Figure 7. The device with a 15-nm-thick silicon oxynitride layer shows a higher HRS, IRS, and LRS current than the devices with thinner layers, which implies that the 15-nm-thick $\mathrm{SiO}_{x} \mathrm{~N}_{\mathrm{y}}$ switching layer more likely hosts more nitride-related traps and oxygen vacancies. A similar phenomenon was reported in [35] and [55], where a thicker oxide layer and silicon nitride layer hosted more oxygen vacancies and more nitride-related traps, respectively. Therefore, the conductivity of the 15-nm-thick $\mathrm{SiO}_{\mathrm{x}} \mathrm{N}_{\mathrm{y}}$ layer is higher than those of the thinner layers. As a result, the formation of conductive paths is easier in the 15-nm-thick $\mathrm{SiO}_{\mathrm{x}} \mathrm{N}_{\mathrm{y}}$ layer than in a 10- or 7-nm-thick layer [56].

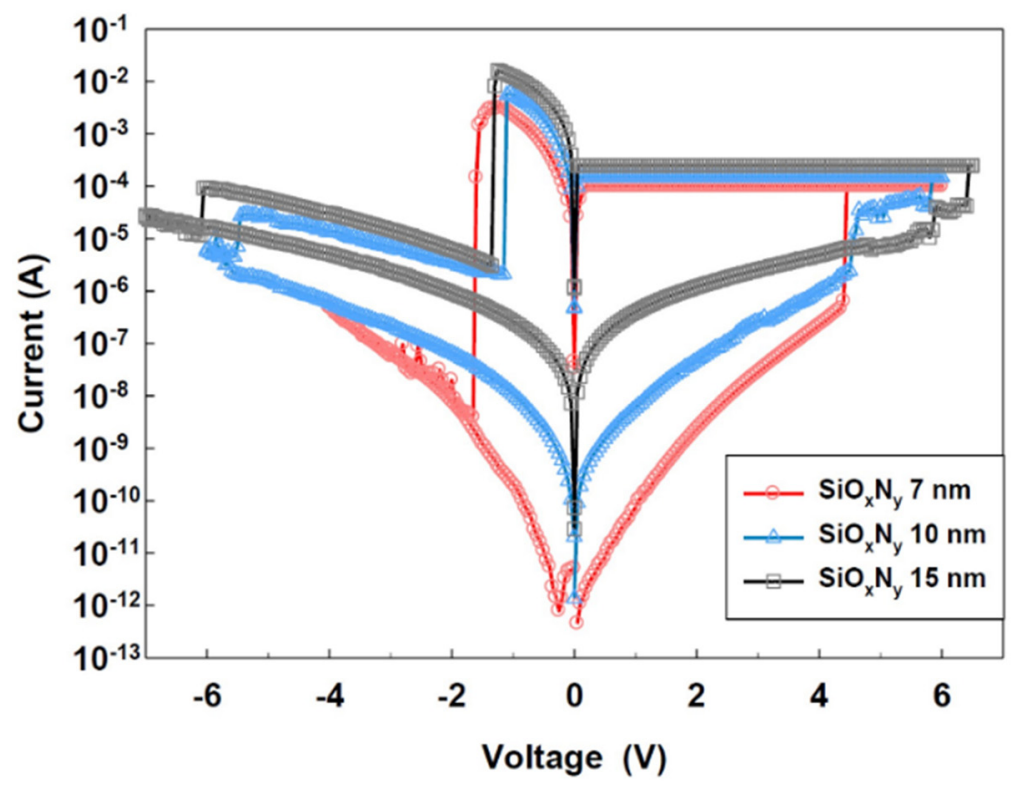

Figure 7. I-V characteristics of $\mathrm{Au} / \mathrm{Ni} / \mathrm{SiO}_{\mathrm{x}} \mathrm{N}_{\mathrm{y}} / \mathrm{p}^{+}-\mathrm{Si}$ memory devices with various $\mathrm{SiOxNy}$ thicknesses.

The SET and RESET voltages for the IRS of the device increase with the increased $\mathrm{SiO}_{\mathrm{x}} \mathrm{N}_{\mathrm{y}}$ layer thickness, which is attributed to the increased number of nitride-related traps and oxygen vacancies in the layer [35]. Meanwhile, the device with a 7-nm-thick silicon nitride layer does not show multilevel switching behavior but rather an electroforming-free bistable resistive switching behavior.

The thickness dependency of the multilevel resisting switching of the RRAM can be explained with the proposed model presented in Figure 5. According to the resistive switching model, the conduction mechanism for the HRS to IRS is due to the trap-to-trap hopping process of the charge carriers and the IRS to LRS is the filament formation at the interface of the $\mathrm{Ni}$ and $\mathrm{SiO}_{\mathrm{x}} \mathrm{N}_{\mathrm{y}}$ layers. A certain thickness of 
the $\mathrm{SiO}_{\mathrm{x}} \mathrm{N}_{\mathrm{y}}$ layer is required for the charge carriers to travel by hopping trap-to-trap from the bottom electrode to the interface of the $\mathrm{Ni}$ and $\mathrm{SiO}_{\mathrm{x}} \mathrm{N}_{\mathrm{y}}$ layers. If the thickness of the $\mathrm{SiO}_{\mathrm{x}} \mathrm{N}_{\mathrm{y}}$ layer is less than the required thickness, the charge carriers can easily move to the interface by tunneling with the small amount of positive bias voltage. Furthermore, the filament formation mechanism takes place which causes the device changing from the HRS to LRS, eliminating the IRS state. As a result, the IRS state is not observed in the 7-nm-thick $\mathrm{SiO}_{\mathrm{x}} \mathrm{N}_{\mathrm{y}}$-based device. It shows a direct change from the HRS to LRS at lower bias voltage than that of the 10 -nm-thick $\mathrm{SiO}_{\mathrm{x}} \mathrm{N}_{\mathrm{y}}$-based device.

The thickness-dependent resistance switching analysis shows that a certain thickness $(10 \mathrm{~nm})$ of the $\mathrm{SiO}_{\mathrm{x}} \mathrm{N}_{\mathrm{y}}$ layer is essential to form the IRS state as well as to obtain three resistance states when the device is fabricated using the process mentioned in this study because the amount of traps and oxygen in the $\mathrm{SiO}_{\mathrm{x}} \mathrm{N}_{\mathrm{y}}$ depends on its thickness. The thickness-dependent resistive switching was also reported by other researchers $[57,58]$.

\subsection{Endurance and Retention Characteristics}

The DC endurance of the $\mathrm{Au} / \mathrm{Ni} / \mathrm{SiO}_{\mathrm{x}} \mathrm{N}_{\mathrm{y}}(10 \mathrm{~nm}) / \mathrm{p}^{+}-\mathrm{Si}$ memory device is shown in Figure 8. The devices were measured under a compliance current of $0.15 \mathrm{~mA}$ and a read voltage of $-0.5 \mathrm{~V}$.

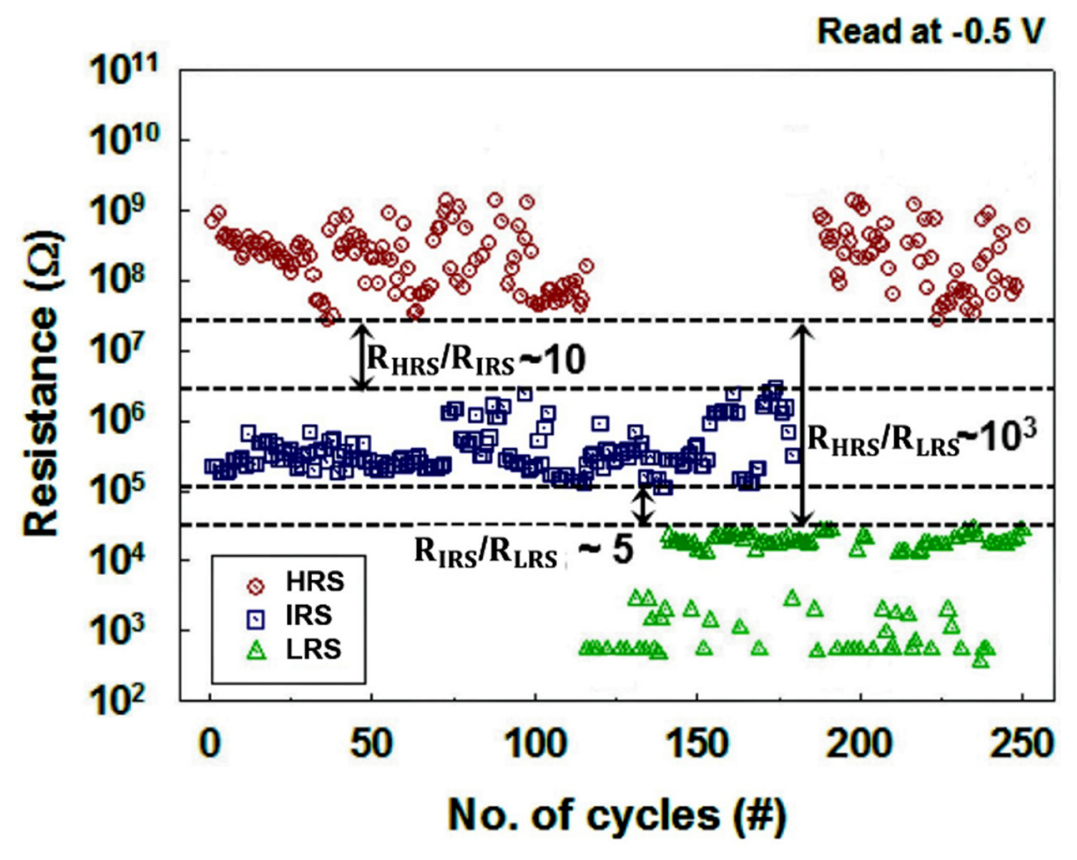

Figure 8. DC endurance property of the $\mathrm{Au} / \mathrm{Ni} / \mathrm{SiO}_{\mathrm{x}} \mathrm{N}_{\mathrm{y}} / \mathrm{p}^{+}-\mathrm{Si}$ memory device.

Under a positive voltage bias, the LRS state is controlled by the compliance current. To obtain the actual LRS current value, a negative bias voltage region was chosen to read values, as there is no compliance current during negative bias. The voltage for RESET1 can vary by -2 to $-1 \mathrm{~V}$, depending on differences in thickness and compliance current. Consequently, $-0.5 \mathrm{~V}$ was selected as the read voltage, to ensure that the measured current was not affected by the compliance current.

To assess the memory device, a total of 250 DC cyclic measurements were performed successively. To confirm the stability of each state, the first 120 cycles were performed while switching between HRS/ IRS, the next 60 cycles were performed between IRS/ LRS, and the last 70 switching cycles were performed between HRS/ LRS. The measured resistance ratios of the various states, $R_{I R S} / R_{H R S}$, $\mathrm{R}_{\mathrm{LRS}} / \mathrm{R}_{\mathrm{IRS}}$, and $\mathrm{R}_{\mathrm{IRS}} / \mathrm{R}_{\mathrm{HRS}}$, were found to be larger than 10,5 , and $10^{3}$, respectively.

In addition, to check the pulse endurance property of the memory device, the SET voltage pulse $(+6.0 \mathrm{~V}, 100 \mathrm{~ms})$ and RESET voltage pulse $(-6.8 \mathrm{~V}, 100 \mathrm{~ms})$ were generated by a waveform generator, and the device state was monitored by using the read pulse $(-0.5 \mathrm{~V}, 100 \mathrm{~ms})$. The pulse endurance of up to 50 cycles for switching between the HRS and IRS was obtained on the $\mathrm{SiO}_{x} \mathrm{~N}_{y}$ device as shown 
in Figure 9. The results show quite distinct HRS and IRS state currents as well as device operation at a low current level.

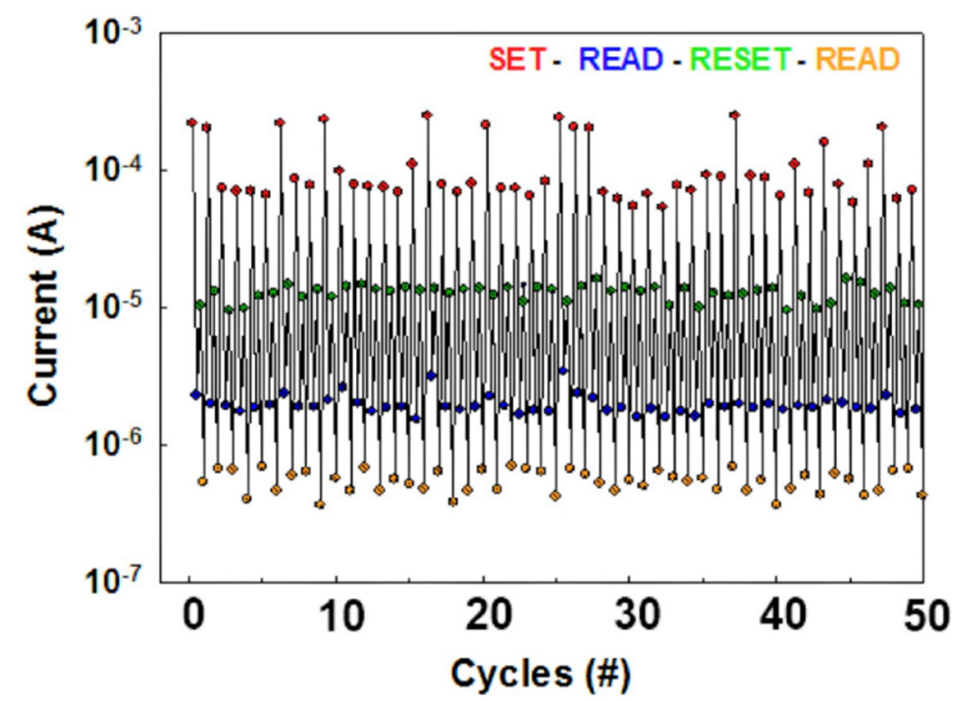

Figure 9. Pulse endurance property of the $\mathrm{Au} / \mathrm{Ni} / \mathrm{SiO}_{\mathrm{x}} \mathrm{N}_{\mathrm{y}} / \mathrm{p}^{+}-\mathrm{Si}$ memory device.

The typical retention behavior of the device is shown in Figure 10 under a reading voltage of $-0.5 \mathrm{~V}$. The device shows excellent retention characteristics as the resistance values in the HRS, IRS, and LRS show no degradation over $1.8 \times 10^{4} \mathrm{sec}$ at $120^{\circ} \mathrm{C}$.

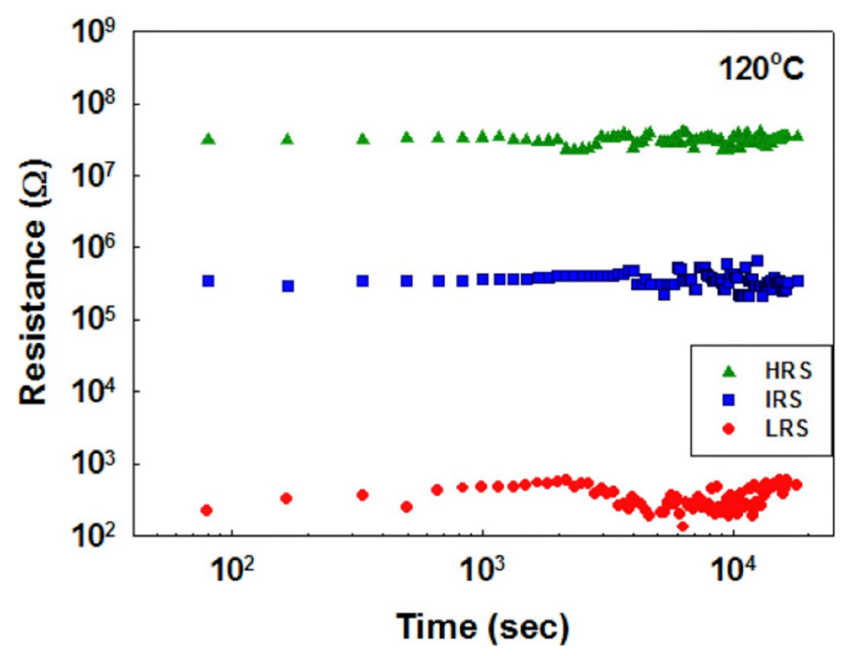

Figure 10. Retention property of the $\mathrm{Au} / \mathrm{Ni} / \mathrm{SiO}_{\mathrm{x}} \mathrm{N}_{\mathrm{y}} / \mathrm{p}^{+}-\mathrm{Si}$ memory device.

\section{Conclusions}

A silicon oxynitride $\left(\mathrm{SiO}_{\mathrm{x}} \mathrm{N}_{\mathrm{y}}\right)$-based nonvolatile resistive switching memory device exhibiting electroforming-free, multilevel bipolar switching characteristics was successfully fabricated by employing a $\mathrm{p}^{+}-\mathrm{Si}$ substrate and $\mathrm{Au} / \mathrm{Ni}$ as the bottom and top electrodes, respectively. The device exhibits multilevel resistive switching from HRS to IRS, IRS to LRS, HRS to LRS, and vice versa. The switching mechanism was explained based on the I-V characteristics of the devices. The resistive switching between HRS and IRS is attributed to the electronic charge trapping and detrapping from the defects present in the bulk $\mathrm{SiO}_{\mathrm{x}} \mathrm{N}_{\mathrm{y}}$ layer. The resistive switching between the IRS and LRS is attributed to the formation and rupture of filaments at the $\mathrm{Ni} / \mathrm{SiO}_{\mathrm{x}} \mathrm{N}_{\mathrm{y}}$ interface region. Both types of switching can be controlled by the magnitude of the applied voltage and the compliance current. The variation of the write current influences the switching performance in the filamentary mode of the interface region, and the variation of the thickness affects the switching performance in the bulk $\mathrm{SiO}_{\mathrm{x}} \mathrm{N}_{\mathrm{y}}$ layer. 
Author Contributions: Each co-author contributed equally. All authors have read and agreed to the published version of the manuscript.

Funding: This work was supported in part by the Creative Materials Discovery Program through the National Research Foundation of Korea (NRF) funded by the Ministry of Science and ICT (NRF-2017M3D1A1040828) and Samsung Electronics.

Conflicts of Interest: The authors declare no conflict of interest.

\section{References}

1. Meijer, G. Materials science: Who wins the nonvolatile memory race? Science 2008, 319, 1625-1626. [CrossRef] [PubMed]

2. Sawa, A. Resistive switching in transition metal oxides. Mater. Today 2008, 11, 28-36. [CrossRef]

3. Waser, R.; Aono, M. Nanoionics-based resistive switching memories. Nat. Mater. 2007, 6, 833-840. [CrossRef] [PubMed]

4. Seok, J.Y.; Song, S.J.; Yoon, J.H.; Yoon, K.J.; Park, T.H.; Kwon, D.E.; Lim, H.; Kim, G.H.; Jeong, D.S.; Hwang, C.S. A Review of three-dimensional resistive switching cross-bar array memories from the integration and materials property points of view. Adv. Funct. Mater. 2014, 24, 5316-5339. [CrossRef]

5. Menzel, S.; Böttger, U.; Waser, R. Simulation of multilevel switching in electrochemical metallization memory cells. J. Appl. Phys. 2012, 111, 014501. [CrossRef]

6. Balatti, S.; Larentis, S.; Gilmer, D.C.; Ielmini, D. Multiple memory states in resistive switching devices through controlled size and orientation of the conductive filament. Adv. Mater. 2013, 25, 1474-1478. [CrossRef]

7. Yu, S.; Gao, B.; Fang, Z.; Yu, H.; Kang, J.; Wong, H.-S.P. A low energy oxide-based electronic synaptic device for neuromorphic visual systems with tolerance to device variation. Adv. Mater. 2013, 25, 1774-1779. [CrossRef]

8. Jo, S.H.; Chang, T.; Ebong, I.; Bhadviya, B.B.; Mazumder, P.; Lu, W. Nanoscale memristor device as synapse in neuromorphic systems. Nano Lett. 2010, 10, 1297-1301. [CrossRef]

9. Chien, W.C.; Chen, Y.C.; Chang, K.P.; Lai, E.K.; Yao, Y.D.; Lin, P.; Gong, J.; Tsai, S.C.; Hsieh, S.H.; Chen, C.F.; et al. Multi-level operation of fully CMOS compatible WOX Resistive Random Access Memory (RRAM). In Proceedings of the 2009 IEEE International Memory Workshop, Monterey, CA, USA, 10-14 May 2009.

10. Reddy, V.S.; Karak, S.; Dhar, A. Multilevel conductance switching in organic memory devices based on AlQ3 and $\mathrm{Al} / \mathrm{Al}_{2} \mathrm{O}_{3}$ core-shell nanoparticles. Appl. Phys. Lett. 2009, 94, 173304. [CrossRef]

11. Russo, U.; Kamalanathan, D.; Ielmini, D.; Lacaita, A.L.; Kozicki, M.N. Study of multilevel programming in Programmable Metallization Cell (PMC) Memory. IEEE Trans. Electron Devices 2009, 56, 1040-1047. [CrossRef]

12. Li, Y.; Long, S.; Liu, Q.; Wang, Q.; Zhang, M.; Lv, H.; Shao, L.; Wang, Y.; Zhang, S.; Zuo, Q.; et al. Nonvolatile multilevel memory effect in $\mathrm{Cu} / \mathrm{WO}_{3} / \mathrm{Pt}$ device structures. Phys. Status Solidi (RRL) -Rapid Res. Lett. 2010, 4, 124-126. [CrossRef]

13. Jo, S.H.; Lu, W. CMOS compatible nanoscale nonvolatile resistance switching memory. Nano Lett. 2008, 8 , 392-397. [CrossRef] [PubMed]

14. Tang, G.S.; Zeng, F.; Chen, C.; Liu, H.Y.; Gao, S.; Li, S.Z.; Song, C.; Wang, G.Y.; Pan, F. Resistive switching with self-rectifying behavior in $\mathrm{Cu} / \mathrm{SiOx} / \mathrm{Si}$ structure fabricated by plasma-oxidation. J. Appl. Phys. 2013, 113, 244502. [CrossRef]

15. Heo, S.; Lee, J.; Kim, S.H.; Yun, D.-J.; Park, J.-B.; Kim, K.; Kim, N.; Kim, Y.; Lee, D.; Kim, K.-S.; et al. Device performance enhancement via a Si-rich silicon oxynitride buffer layer for the organic photodetecting device. Sci. Rep. 2017, 7. [CrossRef] [PubMed]

16. Kapoor, V.; Bailey, R.S.; Smith, S.R. Impurities-related memory traps in silicon nitride thin films. J. Vac. Sci. Technol. 1981, 18, 305-308. [CrossRef]

17. Chen, D.; Huang, S.; He, L. Effect of oxygen concentration on resistive switching behavior in silicon oxynitride film. J. Semicond. 2017, 38, 043002. [CrossRef]

18. Yang, P.-C.; Chang, T.-C.; Chen, S.-C.; Lin, Y.-S.; Huang, H.-C.; Gan, D.-S. Influence of bias-induced copper diffusion on the resistive switching characteristics of a SiON thin film. Electrochem. Solid -State Lett. 2011, 14. [CrossRef] 
19. Yang, J.J.; Pickett, M.D.; Li, X.; Ohlberg, D.A.A.; Stewart, D.R.; Williams, R.S. Memristive switching mechanism for metal/oxide/metal nanodevices. Nat. Nanotechnol. 2008, 3, 429-433. [CrossRef]

20. Wong, H.-S.P.; Lee, H.-Y.; Yu, S.; Chen, Y.-S.; Wu, Y.; Chen, P.-S.; Lee, B.; Chen, F.T.; Tsai, M.-J. Metal-Oxide RRAM. In Proceedings of the 2012 IEEE International Conference on Information Science and Technology, Wuhan, China, 23-25 March 2012; Volume 100, pp. 1951-1970.

21. Münstermann, R.; Yang, J.J.; Strachan, J.P.; Medeiros-Ribeiro, G.; Dittmann, R.; Waser, R. Morphological and electrical changes in $\mathrm{TiO}_{2}$ memristive devices induced by electroforming and switching. Phys. Status Solidi (RRL) -Rapid Res. Lett. 2010, 4, 16-18. [CrossRef]

22. Lee, D.; Seong, D.-J.; Choi, H.J.; Jo, I.; Dong, R.; Xiang, W.; Oh, S.; Pyun, M.; Seo, S.-O.; Heo, S.; et al. Excellent uniformity and reproducible resistance switching characteristics of doped binary metal oxides for non-volatile resistance memory applications. In Proceedings of the 2006 International Electron Devices Meeting, San Francisco, CA, USA, 11-13 December 2006.

23. Kwon, D.-H.; Kim, K.M.; Jang, J.H.; Jeon, J.M.; Lee, M.H.; Kim, G.H.; Li, X.-S.; Park, G.-S.; Lee, B.; Han, S.; et al. Atomic structure of conducting nanofilaments in $\mathrm{TiO}_{2}$ resistive switching memory. Nat. Nanotechnol. 2010, 5, 148-153. [CrossRef]

24. Fang, Z.; Yu, H.Y.; Li, X.; Singh, N.; Lo, G.Q.; Kwong, D.L. $\mathrm{HfO}_{\mathbf{x}} / \mathrm{TiO}_{\mathrm{x}} / \mathrm{HfO}_{\mathrm{x}} / \mathrm{TiO}_{\mathrm{x}}$ multilayer-based forming-free RRAM devices with excellent uniformity. IEEE Electron Device Lett. 2011, 32, 566-568. [CrossRef]

25. Wan, Z.; Darling, R.B.; Majumdar, A.; Anantram, M.P. A forming-free bipolar resistive switching behavior based on ITO/ $\mathrm{V}_{2} \mathrm{O}_{5} / \mathrm{ITO}$ structure. Appl. Phys. Lett. 2017, 111, 041601. [CrossRef]

26. Chien, W.; Chen, Y.; Chen, Y.; Chuang, A.T.; Lee, F.; Lin, Y.; Lai, E.; Shih, Y.; Hsieh, K.; Lu, C.-Y. A forming-free $\mathrm{WO}_{\mathrm{x}}$ resistive memory using a novel self-aligned field enhancement feature with excellent reliability and scalability. In Proceedings of the 2010 International Electron Devices Meeting, San Francisco, CA, USA, 6-8 December 2010.

27. Kawai, M.; Ito, K.; Ichikawa, N.; Shimakawa, Y. Thermally formed conducting filaments in a single-crystalline $\mathrm{NiO}$ thin film. Appl. Phys. Lett. 2010, 96, 072106. [CrossRef]

28. Chen, Y.-S.; Lee, H.-Y.; Chen, P.-S.; Wu, T.-Y.; Wang, C.-C.; Tzeng, P.-J.; Chen, F.; Tsai, M.-J.; Lien, C. An ultrathin forming-free $\mathrm{HfO}_{x}$ resistance memory with excellent electrical performance. IEEE Electron Device Lett. 2010, 31, 1473-1475. [CrossRef]

29. Cao, X.; Li, X.; Gao, X.; Yu, W.; Liu, X.; Zhang, Y.; Chen, L.; Cheng, X. Forming-free colossal resistive switching effect in rare-earth-oxide Gd2O3 films for memristor applications. J. Appl. Phys. 2009, 106, 073723. [CrossRef]

30. Shams, Q.A. Physical and electrical properties of memory quality PECVD silicon oxynitride. J. Electrochem. Soc. 1990, 137, 1244. [CrossRef]

31. Criado, D.; Alayo, M.; Pereyra, I.; Fantini, M. Structural analysis of silicon oxynitride films deposited by PECVD. Mater. Sci. Eng. B 2004, 112, 123-127. [CrossRef]

32. Ay, F.; Aydinli, A. Comparative investigation of hydrogen bonding in silicon based PECVD grown dielectrics for optical waveguides. Opt. Mater. 2004, 26, 33-46. [CrossRef]

33. Hitchman, M.L.; Jensen, K.F. Chemical Vapor Deposition: Principles and Applications; Academic Press: London, UK, 1993.

34. Shi, Y.; He, L.; Guang, F.; Li, L.; Xin, Z.; Liu, R. A Review: Preparation, performance, and applications of silicon oxynitride film. Micromachines 2019, 10, 552. [CrossRef]

35. Kim, H.-D.; An, H.-M.; Kim, K.C.; Seo, Y.; Nam, K.-H.; Chung, H.-B.; Lee, E.B.; Kim, T.G. Large resistive-switching phenomena observed in $\mathrm{Ag} / \mathrm{Si}_{3} \mathrm{~N}_{4} / \mathrm{Al}$ memory cells. Semicond. Sci. Technol. 2010, 25, 065002. [CrossRef]

36. Park, J.H.; Kim, H.-D.; Hong, S.M.; Yun, M.J.; Jeon, D.S.; Kim, T.G. Improved resistive switching phenomena observed in $\mathrm{SiN}_{\mathrm{x}}$-based resistive switching memory through oxygen doping process. Phys. Status Solidi (RRL) -Rapid Res. Lett. 2013, 8, 239-242. [CrossRef]

37. Xu, N.; Gao, B.; Liu, L.; Sun, B.; Liu, X.; Han, R.; Kang, J.; Yu, B. A unified physical model of switching behavior in oxide-based RRAM. In Proceedings of the 2008 Symposium on VLSI Technology, Honolulu, HI, USA, 17-19 June 2008.

38. Ielmini, D.; Spiga, S.; Nardi, F.; Cagli, C.; Lamperti, A.; Cianci, E.; Fanciulli, M. Scaling analysis of submicrometer nickel-oxide-based resistive switching memory devices. J. Appl. Phys. 2011, 109, 034506. [CrossRef] 
39. Rebib, F.; Tomasella, E.; Dubois, M.; Cellier, J.; Sauvage, T.; Jacquet, M. Structural and optical investigations of SiOxNy thin films deposited by R.F. sputtering. Surf. Coat. Technol. 2005, 200, 330-333. [CrossRef]

40. Chen, W.S.; Chen, Y.S.; Hsu, Y.Y.; Yang, S.Y.; Liu, W.H.; Lee, H.Y.; Gu, P.Y.; Tsai, C.H.; Wang, S.M.; Chen, P.S.; et al. IC process compatible anodic electrode structures for unipolar HfOx-based RRAM. In Proceedings of the 2011 International Symposium on VLSI Technology, Systems and Applications, Taiwan, China, 25-27 April 2011.

41. Li, L.; Yang, X.; Lei, Y.; Yu, H.; Yang, Z.; Zheng, Z.; Wang, D. Ultrathin Fe-NiO nanosheets as catalytic charge reservoirs for a planar Mo-doped $\mathrm{BiVO}_{4}$ photoanode. Chem. Sci. 2018, 9, 8860-8870. [CrossRef]

42. Wu, H.; Wang, L.-S. A study of nickel monoxide $(\mathrm{NiO})$, nickel dioxide $(\mathrm{ONiO})$, and $\mathrm{Ni}\left(\mathrm{O}_{2}\right)$ complex by anion photoelectron spectroscopy. J. Chem. Phys. 1997, 107, 16-21. [CrossRef]

43. Available online: http://www2.ucdsb.on.ca/tiss/stretton/database/inorganic_thermo.htm (accessed on 25 April 2020).

44. Available online: http://www.colby.edu/chemistry/PChem/Hartree.html (accessed on 25 April 2020).

45. Kim, K.M.; Choi, B.J.; Koo, B.W.; Choi, S.; Jeong, D.S.; Hwang, C.S. Resistive switching in $\mathrm{Pt} / \mathrm{Al}_{2} \mathrm{O}_{3} / \mathrm{TiO}_{2} / \mathrm{Ru}$ stacked structures. Electrochem. Solid -State Lett. 2006, 9, G343-G346. [CrossRef]

46. Wu, X.; Zhou, P.; Li, J.; Chen, L.Y.; Lv, H.B.; Lin, Y.Y.; Tang, T.A. Reproducible unipolar resistance switching in stoichiometric $\mathrm{ZrO}_{2}$ films. Appl. Phys. Lett. 2007, 90, 183507. [CrossRef]

47. Lin, C.-Y.; Wu, C.-Y.; Wu, C.-Y.; Tseng, T.-Y.; Hu, C. Modified resistive switching behavior of $\mathrm{ZrO}_{2}$ memory films based on the interface layer formed by using Ti top electrode. J. Appl. Phys. 2007, 102, 094101. [CrossRef]

48. Lin, C.-Y.; Wang, S.-Y.; Lee, D.-Y.; Tseng, T.-Y. Electrical properties and fatigue behaviors of $\mathrm{ZrO}_{2}$ resistive switching thin films. J. Electrochem. Soc. 2008, 155. [CrossRef]

49. Yuan, X.-C.; Tang, J.-L.; Zeng, H.-Z.; Wei, X.-H. Abnormal coexistence of unipolar, bipolar, and threshold resistive switching in an $\mathrm{Al} / \mathrm{NiO} / \mathrm{ITO}$ structure. Nanoscale Res. Lett. 2014, 9, 268. [CrossRef]

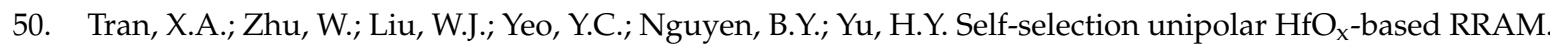
IEEE Trans. Electron Devices 2013, 60, 391-395. [CrossRef]

51. Ielmini, D.; Nardi, F.; Cagli, C. Physical models of size-dependent nanofilament formation and rupture in $\mathrm{NiO}$ resistive switching memories. Nanotechnology 2011, 22, 254022. [CrossRef] [PubMed]

52. Yang, J.J.; Strukov, D.B.; Stewart, D.R. Memristive devices for computing. Nat. Nanotechnol. 2012, 8, 13-24. [CrossRef] [PubMed]

53. Sun, B.; Liu, L.; Xu, N.; Gao, B.; Wang, Y.; Han, D.; Liu, X.; Han, R.; Kang, J. The effect of current compliance on the resistive switching behaviors in $\mathrm{TiN} / \mathrm{ZrO}_{2} / \mathrm{Pt}$ memory device. Jpn. J. Appl. Phys. 2009, 48, $04 \mathrm{C} 061$. [CrossRef]

54. Sun, H.; Liu, Q.; Li, C.; Long, S.; Lv, H.; Bi, C.; Huo, Z.; Li, L.; Liu, M. Direct observation of conversion between threshold switching and memory switching induced by conductive filament morphology. Adv. Funct. Mater. 2014, 24, 5679-5686. [CrossRef]

55. Tendulkar, M.; Gopal, V.; Hashim, I.; Higuchi, R.J.; Minvielle, T.; Wang, Y.; Yamaguchi, T. Bilayered oxide structures for ReRAM cells. U.S. Patent No. 20,140,175,360A1, 26 June 2014.

56. Yoshida, M.; Tohyama, D.; Maeguchi, K.; Kanzaki, K. Increase of resistance to hot carriers in thin oxide MOSFETS. In Proceedings of the 1985 International Electron Devices Meeting, Washington, DC, USA, 1-4 December 1985.

57. Rehman, S.; Khan, M.F.; Aftab, S.; Kim, H.; Eom, J.; Kim, D.-K. Thickness-dependent resistive switching in black phosphorus CBRAM. J. Mater. Chem. C 2019, 7, 725-732. [CrossRef]

58. Nakajima, R.; Azuma, A.; Yoshida, H.; Shimizu, T.; Ito, T.; Shingubara, S. Hf layer thickness dependence of resistive switching characteristics of $\mathrm{Ti} / \mathrm{Hf} / \mathrm{HfO}_{2} / \mathrm{Au}$ resistive random access memory device. Jpn. J. Appl. Phys. 2018, 57, 06HD06. [CrossRef]

(C) 2020 by the authors. Licensee MDPI, Basel, Switzerland. This article is an open access article distributed under the terms and conditions of the Creative Commons Attribution (CC BY) license (http://creativecommons.org/licenses/by/4.0/). 